\title{
Article
}

\section{Inequalities in access to health and social care among adults with multiple sclerosis: A scoping review of the literature}

Roddam, Hazel, Rog, David, Janssen, Jessie, Wilson, Neil, Cross, Lucy, Olajide, Olufemi and Dey, Paola

Available at http://clok.uclan.ac.uk/25901/

Roddam, Hazel ORCID: 0000-0002-0637-1801, Rog, David, Janssen, Jessie ORCID: 0000-0002-5961-2736, Wilson, Neil ORCID: 0000-0003-2235-6086, Cross, Lucy ORCID: 0000-0002-7272-9445, Olajide, Olufemi and Dey, Paola (2019) Inequalities in access to health and social care among adults with multiple sclerosis: A scoping review of the literature. Multiple Sclerosis and Related Disorders, 28 . pp. 290-304. ISSN 2211-0348

It is advisable to refer to the publisher's version if you intend to cite from the work. http://dx.doi.org/10.1016/j.msard.2018.12.043

For more information about UCLan's research in this area go to http://www.uclan.ac.uk/researchgroups/ and search for <name of research Group>.

For information about Research generally at UCLan please go to http://www.uclan.ac.uk/research/

All outputs in CLoK are protected by Intellectual Property Rights law, including Copyright law. Copyright, IPR and Moral Rights for the works on this site are retained by the individual authors and/or other copyright owners. Terms and conditions for use of this material are defined in the policies page. 


\section{Inequalities in access to health and social care among adults with multiple sclerosis: a scoping review of the literature}

Conflict of interest statement:

All authors declare that they have no conflict of interest in submitting this manuscript.

The project was funded by David Rog, Consultant Neurologist, Salford Royal NHS Hospitals Foundation Trust

Hazel Roddam, Reader in Allied Health Practice, School of Health Sciences, University of Central Lancashire, Adelphi Street, Preston, England, PR1 2HE. HRoddam@uclan.ac.uk

David Rog, Consultant Neurologist, Salford Royal NHS Hospitals Foundation Trust, Stott Lane, Salford, M6 8HD David.Rog@srft.nhs.uk

Jessie Janssen, Research Fellow, School of Health Sciences, University of Central Lancashire, Adelphi Street, Preston, England, PR1 2HE. JJanssen@uclan.ac.uk

Neil Wilson, Research Associate, School of Health Sciences, University of Central Lancashire, Adelphi Street, Preston, England, PR1 2HE. NWilson9@uclan.ac.uk

Lucy Cross, Research Assistant, School of Health Sciences, University of Central Lancashire, Adelphi Street, Preston, England, PR1 2HE. LCross1@uclan.ac.uk

Olufemi Olajide, PhD student, School of Dentistry, University of Central Lancashire, Adelphi Street, Preston, England, PR1 2HE. OOlajide@uclan.ac.uk

Paola Dey, Professor of Public Health and Epidemiology, Edge Hill University, St Helens Road, Ormskirk, Lancashire, England L39 4QP paola.dey@edgehill.ac.uk

Corresponding Author: Hazel Roddam, Reader in Allied Health Practice, School of Health Sciences, University of Central Lancashire, Adelphi Street, Preston, England, PR12HE. HRoddam@uclan.ac.uk 


\section{ABSTRACT (300 words unstructured)}

Variations in access to health care are known to contribute to differences in life expectancy, morbidity and health-related quality-of-life across population subgroups. We undertook a scoping review to identify what is known about in-country variations in access to services for adults with multiple sclerosis and to identify gaps in the literature to inform future research and national policies. We searched MEDLINE, CINAHL, EMBASE, PSYCHINFO, SocINDEX and Social Science Abstracts from inception to end of December 2016 for quantitative studies which had investigated differences in access to prevention services, healthcare services, treatments and social care between inequality groups, defined using the PROGRESS-PLUS framework. A total of 4959 unique abstracts yielded 36 papers which met our eligibility criteria. Only 3 studies were cohort studies and only 4 were populationbased; most were from the United States $(n=27)$. There were 6 studies on access to MS focused care and 6 on access to Disease Modifying treatments. There were 3 studies on access to prevention/lifestyle programmes and none on access to welfare services or information support. There were no papers examining inequalities in access for 'vulnerable' groups, such as, those with learning disability. In the available studies, there was evidence of inequalities in access to services with a trend for worse access among men, older age groups, those from lower socioeconomic groups or the least educated, non-caucasians, those with mental health problems and those from rural areas. In the studies on access to disease modifying treatments, older age and lower socioeconomic status were consistently associated with a lower rate of uptake, while race and gender were not. Inequalities or disparities in access to all levels of services and treatments will need to be addressed through a strategic research agenda with an emphasis on populationbased studies and development and evaluation of interventions to reduce inequality. 


\section{INTRODUCTION}

Variations in access to health care are known to contribute to differences in life expectancy, morbidity and health-related quality-of-life across population subgroups [1-4]. When these variations are avoidable they contribute to inequalities or disparities in health experience [5] and have led to international and national strategies to reduce gaps in service provision, particularly, when there is evidence of lack of access to proven effective interventions or clinical variations in care [6-8].

The Multiple Sclerosis Atlas has demonstrated gross international differences in mortality in multiple sclerosis and access to disease modifying treatments [9]. However, studies also suggest variations within countries, with some evidence that place of residence and sociodemographic characteristics (e.g., age, gender and ethnicity) have an influence on patient outcome [10-12]. There is also concern about variations in access to disease modifying treatments for some patient subgroups, which might be, in part, secondary to how health services are organised [13,14]. In chronic conditions like multiple sclerosis (MS), it is also important to consider inequalities in access to services and treatments which reduce morbidity across the care pathway, from secondary prevention to rehabilitation and social care [15]. The complex needs of many patients with MS require the input of many other services, such as physiotherapy, occupational therapy and mental health services, as these treatments/therapies have been shown to reduce morbidity in MS [16-18]. Independence and participation may be maintained through social support, personal support and housing adaptations, and the employment consequences of an MS diagnosis through vocational rehabilitation [19]. More recently, there has been a greater focus on improving well-being through promoting healthy lifestyles among adults with multiple sclerosis, because of evidence that increased physical activity helps to maintain physical functioning and improve mental health in MS patients [20] and because smoking may raise the risk of disease progression [21]. Therefore, variations in access to lifestyle and prevention programmes is also important.

We undertook a scoping review of the literature to identify what is known about incountry variations in access to services for adults with MS and to identify gaps in the literature to inform future research and national policies. A scoping review uses systematic methods to identify the literature but addresses a broader question than a systematic review. As such, it is less concerned with the reporting quality of the papers or meta-analysis. In this scoping review, we identified and reviewed studies which used a quantitative methodology to investigate intra-national (in-country) variations in access across the care pathway and health systems of different inequality groups among populations of adult MS patients.

\section{METHODS}

Although this study was not focused on the effectiveness of interventions to reduce inequity, we used the Joanna Briggs Institute guidance on scoping reviews [22] and the Cochrane and Campbell Equity methods group checklist [23] to guide the 
development of the study protocol, study implementation and presentation of findings. This study was funded by Salford Royal NHS Hospitals Foundation Trust.

Definition of exposures (Inequality groups)

We used the PROGRESS-PLUS framework for determining inequality groups in this review [24]. These were used to guide terms in the search strategy and to stratify studies in the analysis. In this framework the PROGRESS inequality groups (place of residence, race/ethnicity/culture/language, occupation/employment status, gender/sex, religion, education, socio-economic status, and social capital) were supplemented by 'PLUS' inequality groups related to personal characteristics pertinent to MS patients: age, disability (physical +/or cognitive), disease type, mental health conditions, and other 'vulnerable groups', e.g., learning difficulties, travelers, migrants. The 'PLUS' groups were chosen based on the potential for barriers to access of services and/or treatments following discussion within the review team, which consisted of clinicians and public health professionals. When considering social capital, we took a broad and inclusive approach to its definition and included all aspects of social networks and social cohesion under this umbrella term [25]. We also included a broad range of indicators of socioeconomic status, e.g, deprivation indices, income.

\section{Definition of outcomes (programmes/services/treatments)}

À priori, we broadly categorised the programmes/services/treatments and, post-hoc, agreed subcategories for presentation when studies were found. The categories (and subcategories) included: prevention programmes (subcategories: primary and secondary prevention), diagnostic investigations, medical care (subcategories: medication general, disease modifying treatments, general health care, neurology services, MS specific services, health provider systems e.g., health maintenance organisation), mental health services, rehabilitation services, social and welfare services (personal support, housing, assisted devices or assisted living) and information support.

Eligibility criteria

We included studies with a quantitative research design from any country and healthcare setting if they compared inequality MS groups as to uptake of, or access to programmes, services or treatments across the prevention/care/support pathway. Participants could have any type or stage of MS and be at any time following diagnosis. As the focus was on adult MS patients, we excluded any study in which more than $5 \%$ of the population was under 16 years of age. We also excluded studies comparing MS patients with the general population or with other patient groups, studies investigating uptake of alternative or complementary therapies, those that focused on uptake of lifestyles rather than the services which promote lifestyle 
modification, those investigating DMT adherence rather than prescription and studies where the outcome was perceived or reported need, rather than comparative need.

Search strategy

We searched MEDLINE, CINAHL, EMBASE, PSYCHINFO, SocINDEX and Social Science Abstracts from inception to end of December 2016 using the key terms for multiple sclerosis as recommended by the Cochrane Multiple Sclerosis and Rare Diseases Review Group [26] and search terms for inequalities/disparities and the inequality groups, adapted as appropriate for the different databases. The search was limited to English Language articles. The full search strategy for MEDLINE (EBSCO) is included in supplementary materials (supplementary table 1). The titles and abstracts were screened by teams of two authors independently and any conflicts resolved by a third reviewer. RESULTS

A total of 4959 unique abstracts were identified from the databases following automatic removal of duplicates. This yielded 157 full text papers for eligibility screening and a further paper was identified from other sources [15]. A total of 36 papers were deemed eligible for further analysis [15, 27-61]. Reasons for exclusion for the other 122 papers included: a lack of focus on inequality $(n=23)$; non-eligible study design $(n=26)$; non-eligible study population $(n=18)$; exposures inconsistent with the PROGRESS-PLUS framework $(n=27)$ or lack of data on access to a service or treatment $(n=28)$. Figure 1 shows the flow diagram of search results.

Figure 1: Flow chart of search 


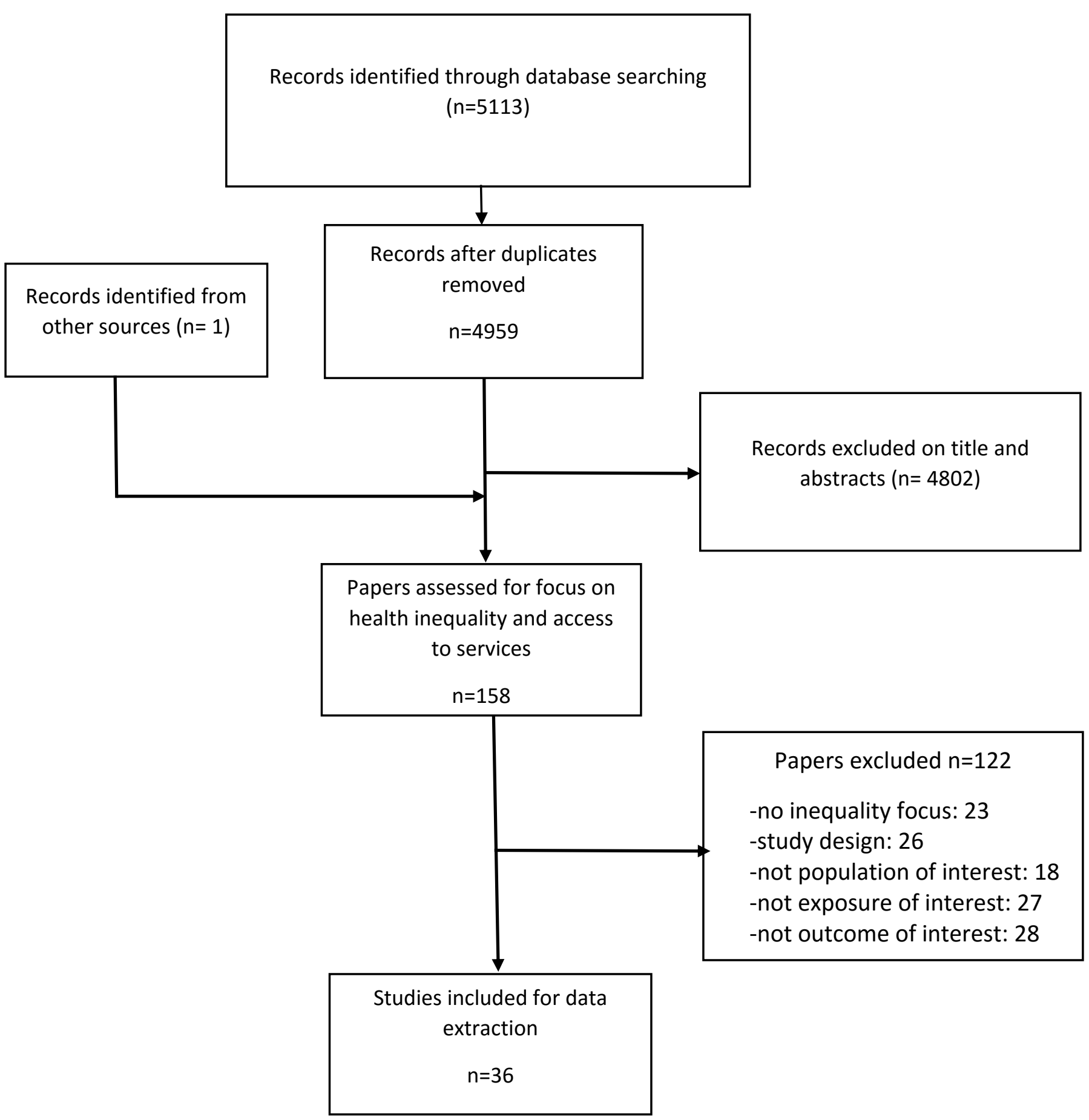

3 The full characteristics of the 36 studies is shown in supplementary table 2 . Only 3 4 studies were cohort studies [28, 47,55$]$ and only 4 were population-based [46, 47 , 5 52, 58]. The data source for 12 of the 36 was in full, or in part, from the members of 6 National Multiple Sclerosis Society [32, 33, 36, 37, 41, 42, 43, 48, 49, 53, 54, 56] and 7 for 4 studies the North American Research Committee on Multiple Sclerosis

8 (NARCOMS) register [30, 44, 45, 56]. There were also 4 studies which used the 9 Minimum Data Set (MDS) for Medicare/Medicaid certified Nursing Homes (two of 10 which used the same sample) $[29,31,34,35]$ and 3 which drew on a single survey 11 ("Aging With MS: Unmet Needs in the Great Lakes Region" survey) [38, 39, 40]. The 
studies were published between 2000 and 2016 with 10 studies published since $2010[30,38,39,46,47,51,53,55,56,61]$. Most of the studies were undertaken in the US $(n=27)$ and all studies were undertaken in North America or Western Europe.

$4 \quad$ Figure 2 and table 1 show the numbers of studies focusing on the different access outcome categories and subcategories. There were 10 unique studies on access to medical services, of which, six studies were on access to MS focused care. Eight unique studies focused on access to medications, of which, 6 were on access to Disease Modifying treatments. A similar number of papers were on access to mental health services $(n=7)$, rehabilitation $(n=8)$, and social support/care $(n=7)$. There were a few studies on diagnostic services $(n=2)$, access to prevention/lifestyle programmes $(n=3)$ and on housing adaptions or aids $(n=4)$, but no studies on access to welfare services or information support. All three studies about inequalities in access to health provider systems were from the United States.

Figure 2: Number of papers by access subcategory

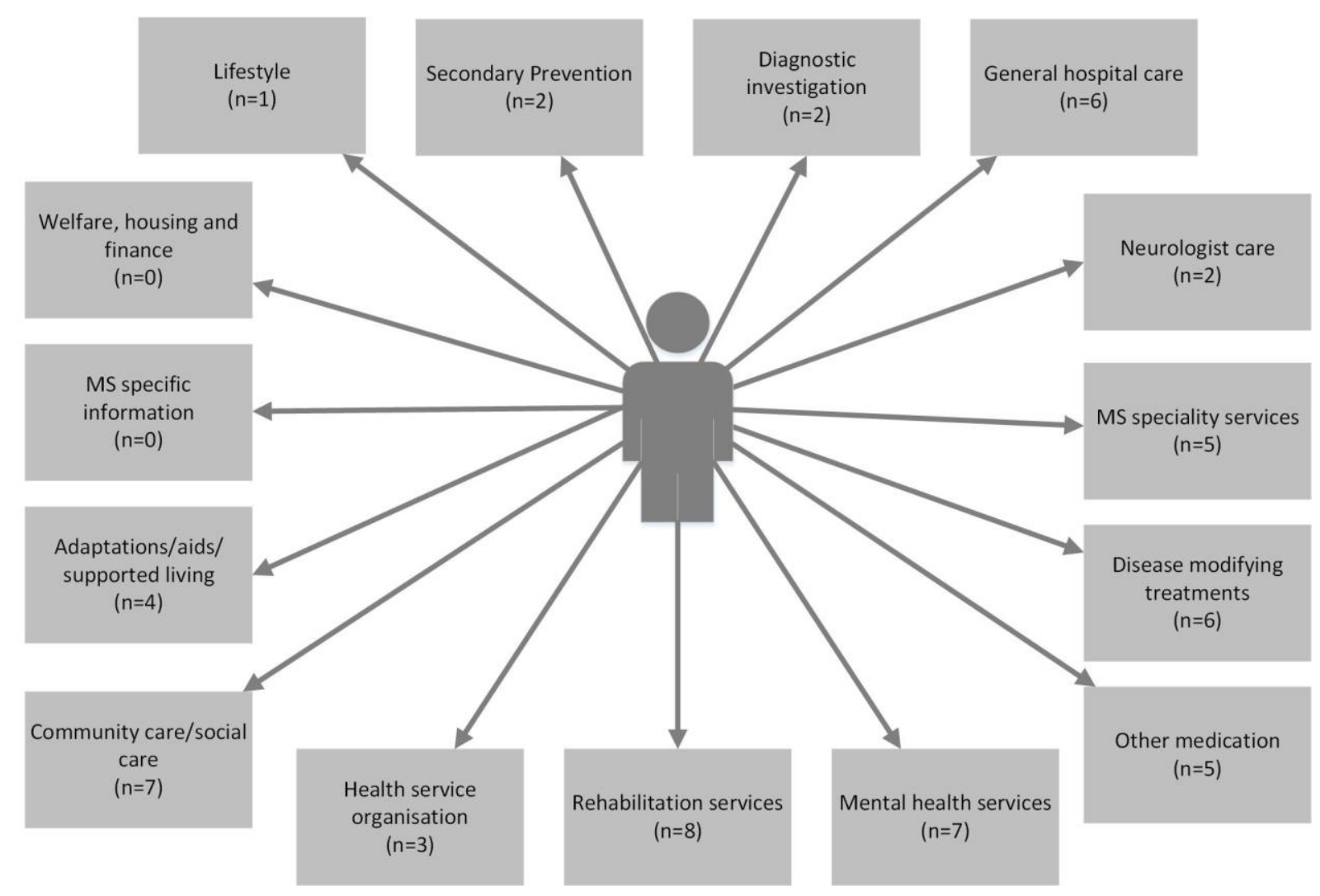

Table 1 summary of findings here (see separate file)

The effect of gender was examined across all access subcategories for which there were studies, and disability and socioeconomic status across all but one. Gender $(n=25)$, age $(n=21)$ and disability $(n=18)$ were most frequently included as exposure factors. In contrast, mental health status ( $n=9)$, occupation, i.e., employment status, 
$1 \quad(n=9)$, and disease type $(n=7)$ were less frequently examined. Given the setting of

2 most of the papers, the 15 studies about race mainly focused on differences

3 between Caucasian, African American and Hispanic populations. Those on place

$4 \quad(n=13)$ compared urban and rural populations and all the papers categorised under

5 social capital $(n=14)$ were on marital status or living arrangements. There were no

6 papers examining 'vulnerable' groups or religion as factors affecting access to

7 services/treatments.

8 The findings for each access category is shown in table 1. There was evidence of

9 inequalities in access to services, but the relationship was not consistent across

10 access subcategories. Broadly, there was a trend for worse access among men,

11 older age groups, those from lower socio-economic groups or the least educated, However these findings were not universal, for example, women were less likely than men to see a urologist or have a powered wheelchair, and younger patients were less likely to be in receipt of personal assistance. In the studies on access to disease modifying treatments, older age and lower socioeconomic status were consistently associated with a lower rate of uptake, while race and gender were not. The relationship between severity of disability and levels of access across the care pathway was complex; with evidence of worse access to primary prevention and neurology services, no evidence of access issues to MS specific care and better access to rehabilitation, social care and assisted living.

\section{DISCUSSION}

In the limited number of studies identified, the findings of this scoping review support the existence of inequality, or disparity, in access to services among MS subpopulations within countries. The subpopulations experiencing inequality are similar to those experiencing access or uptake issues in other conditions. For example, in cancer screening men, minority ethnic groups and those from more deprived areas have lower rates of bowel screening [62]; older adults are less likely to receive proven effective treatments [63]; and rurality has been associated with lower access to specialist services [64]. However, this review also suggests that interpreting variations in access rates as an inequality or disparity is complex. There was some evidence that inequalities may be context specific. For example, women rather than men were less likely to be referred to a urologist. Urinary symptoms are very common in multiple sclerosis, but one study suggested that only two thirds of patients are asked about these symptoms by their clinician [65]. Gender disparity in referral to urologists has also been observed in general populations with haematuria and voiding difficulties, with women less likely to be referred and more likely to be treated for urinary tract infections [66,67]. Depending on the population subgroup, a higher or a lower uptake rate might be interpreted as an inequality for the same service. For example, in the study by Marrie [46], access to ICU was lower among those living in rural areas, which might suggest that because of the distance from specialist services those in rural areas could not obtain necessary management. However, access to intensive care units (ICU) was higher among men and older 
1 patients. This could be interpreted as women and younger patients being less likely

2 to benefit from necessary care; but equally could be interpreted that men and older

3 patients are less likely to receive appropriate care to prevent overwhelming

4 infections. Similarly, a lower rate of access to lifestyle interventions among those

5 who are more disabled may be an inequality if they can benefit from these services;

6 whereas a lower rate of access to home adaptations among those who are less

7 disabled may not be an inequality, if they do not need such aids. These examples

8 highlight the need for research to understand the reasons for differences between

9 population subgroups: whilst some of these are likely to be similar to those

10 experienced by adults with other co-morbidities [68], some are likely to be disease

11 specific. Such research will also facilitate the development of strategies to reduce

12 important variations.

13 Further difficulties in interpretation were introduced by the study designs. Few outcome were measured at the same time. While this may not affect some exposures (such as gender), the interpretation of the direction of effect can be more problematic for exposures such as mental health or disability. So for example, in the study by Buchanan et al, nursing residents who were depressed were less likely to have occupational therapy (OT) [29]. As this was a cross-sectional study, it was unclear whether they had less OT because they were depressed, or not having OT made them depressed. Furthermore, there were other concerns about the quality of these studies: not all studies undertook a multivariate analysis to assess whether the exposures were independent risk factors. Few studies were population-based and many relied on members of MS societies: these groups might be less likely to include those from lower socio-economic groups, the less educated and minority groups [42, 43]. Finally, the generalisability of the findings may be limited because the majority were undertaken in US and all within western developed countries. Even then, the organisation and funding of health and social care systems in the US and the geography and racial breakdown are substantially different to that of, for example, the United Kingdom, where only 3 studies have been undertaken [15, 51, 52].

There were a relatively high number of studies investigating access to disease modifying treatments. This is perhaps unsurprising, given the controversies around funding of these effective but expensive drugs; particularly when they first came to market [51]. More recent studies suggest that in addition to concerns about socioeconomic disadvantage having an impact on access to first line Disease Modifying Treatments (DMTs), there still remain concern about access of patients from lower socioeconomic groups to second line treatments [69]. There were very few studies about prevention programmes, which might reflect the relative recency of the interest in lifestyle interventions to promote well-being in MS populations. Nevertheless, promotion of physical activity, safe alcohol consumption and smoking cessation are incorporated into some national guidelines for MS care [70], and further work on access to these interventions overall and across inequality groups is warranted. It is perhaps more surprising that there were no studies on access to vocational rehabilitation services, and few on the impact of unemployment on access 
to services, given the considerable research on the difficulties encountered by adults with MS within the workplace and the detrimental impact of unemployment on their well-being $[71,72]$. We also found no studies about access to informational support. There is increasing interest in developing self-management programmes including digital technology for patients. While such programmes are important to promote well-being and patient engagement [13], there is the potential for introducing further health inequalities, as access to and use of the internet or mobile devices differs across socioeconomic and racial groups [73].

As well as the difficulties in interpretation, there were other limitations to our scoping review. Because of resource limitations, only studies in the English language were included. This may in part account for the observation that there were relatively few countries included among the eligible studies. We specifically excluded studies which focused only on perceived or expressed needs, as these are subjective. Studies reporting objectively measured needs were included, but perceived or expressed needs may under represent genuine inequalities as they may represent wants, although studies have shown that these can vary across inequality group [74]. We did not include qualitative studies as the objective was to compare across inequality groups, but these types of studies would give greater depth of understanding of why inequalities exist. Finally, the concluding step in Arksey and O'Malley's original structure for scoping reviews includes a discussion with stakeholders of the findings [75]. This has not been formally undertaken with external stakeholders, but was addressed internally by the review team which included both researchers and clinicians. A recent scoping review on the conduct and reporting of scoping reviews suggests relatively few published scoping reviews undertake this step [76].

\section{CONCLUSION}

This scoping review was essential to benchmark the current evidence base and to demonstrate the paucity of published studies to date for this population. It has identified that inequalities exist throughout the prevention, care and support pathway for adults with MS, but the interpretation of these findings are limited by the lack of consistency between studies and across different types of care or support. In part, this may be because inequality is likely to be context specific and, in part, because of the limitations of the study design. There were also some specific research gaps identified, particularly in relation to prevention, vocational support and patient information and within inequality groups, learning disabilities and other 'vulnerable' groups. Inequalities or disparities in access to all levels of services and treatments will need to be addressed through a strategic research agenda. Further research to explore these areas requires large-scale population-based databases to ensure that participants are representative. Longitudinal studies also need to be responsive to changes in evidence about the management and treatment of MS. Further research is needed into understanding the reasons for differences in access to develop strategies to address any inequality. The findings of this scoping review will help to inform the prioritisation of future research for this population internationally. 


\section{REFERENCES}

3 1. Cookson R, Asaria M, Ali S et al. Health Equity Indicators for the English NHS; a

4 longitudinal whole-population study at the small area level. Southhampton (UK):

$5 \quad$ NIHR Journals Library. 2016 (Sept)

6 2. Judge A, Welton NJ, Sandhu J, Ben Shlomo Y. Equity in access to total joint

7 replacement of the hip and knee in England: cross-sectional study. BMJ.

$8 \quad 2010 ; 341: c 4092$

9 3. Karanikolos M, Ellis L, Coleman MP, McKee M. Health systems performance

4. Li Y, Glace LG, Lyness JM et al. Mental illness, access to hospitals with invasive cardiac procedures by Medicaid acute myocardial infarction patients. Health Serv Res. 2013;48(3):1076-95

5. World Health Organisation Commission on the Social Determinants of Health, Closing the gap in a generation: health equity through action on the social determinants of health. Geneva, $\mathrm{CH} 2008$

6. Asaria M, Shehzad A, Doran T et al. How a universal health system reduces inequality: lessons from England. J Epid Comm Health. 2016; 70(7); 637-43.

7. Obama B. United States Health Care Reform: Progress to Date and Next Steps. JAMA. 2016;316(5):525-32.

8. World Health Organisation. Taking action to improve health equity. Global Plan of Action on Social Determinants of Health. www.who.int/social determinants/action sdh/en/ accessed 24/6/2018

9. Browne P, Chandraratna D Angood C et al. Atlas of Multiple Sclerosis 2013: a growing problem with widespread inequity. Neurology. 2014;83(11):1022-4.

10. Amezcua L, Rivas E Joseph S et al. Multiple Sclerosis Mortality by race/ethnicity, age and time-period in the United States 1999-2015. Neuroepidemiology. 2018; 50:35-40

11. Cutter CR, Zimmerman J, Salter AR et al. Causes of death among persons with multiple sclerosis. Mult Scher Relat Disord. 2015;4(5): 484-90.

12. Landtblom AM, Riise T, Boito A, Soderfeldt B. Distribution of Multiple Sclerosis in Sweden based on mortality and compensation statistics.

Neuroepidemiology. 2002 Jul-Aug;21(4):167-79

13. Marziniak M, Ghorals K, Kozubski W et al. Variations in multiple sclerosis practice within Europe: is it time for a new treatment guideline? Multiple Sclerosis and related disorders. 2016;8;35-44. 
1 14. Souliotis K, Alexopoulou E, Papageorgiou M et al. Access to care for multiple

2 sclerosis in thimes of economic crisis in Greece; the Hope II study. Int J Health

3 Policy Manag. 2015;5(2). 83-9.

4 15. Freeman JA and Thompson AJ. Community services in multiple sclerosis: still 5 a matter of chance J Neurol Neurosurg Psychiatry 2000;69:728-732

6 16. Khan F, Amatya B. Rehabilitation in multiple sclerosis: a systematic review of 7 systematic reviews. Arch Phys Med Rehabil. 2017;98(2):353-67.

17. Baker NA, Tickle-Degnen L. The effectiveness of physical, psychological and functional intervention in treating clients with multiple sclerosis: a metaanalysis. Am $\mathrm{J}$ of occupational therapy. $2001 ; 55(3) ; 324-31$.

18. Fiest KM, Walker JR, Bernstein $\mathrm{CN}$ et al. Systematic review and metaanalysis of interventions for depression and anxiety in persons with multiple sclerosis. Mult Scler Relat Disord. 2016;5:12-26.

19. Costa DC et al 2012 The effect of social support on the quality of life of patients with multiple sclerosis Arq Neuropsiquiatr 2012;70(2):108-113

https://www.ncbi.nlm.nih.gov/pubmed/22311214

20. Halabchi G, Alizaden Z, Sahranian MA and Abolhasani M. Exercise prescription for patients with multiple sclerosis; potential benefits and practical recommendations. BMC Neurology. 2017;17:185.

21. Degelman ML, Herman KM. Smoking and multiple sclerosis: a systematic review and metaanalysis using the Bradford Hill criteria for causation. Mult Scler Related Disorder. 2017;17:207-16.

22. The Joanna Briggs Institute. The Joanna Briggs Institute Scoping Review Manual 2015 edition/ supplement. Methodology for JBI Scoping Reviews. The Joanna Briggs Institute. 2015.

23. Cochrane and Campbell Equity methods group http://methods.cochrane.org/sites/methods.cochrane.org.equity/files/public/uploads/ EquityChecklist2012.pdf Accessed 14 ${ }^{\text {th }}$ May 2018

24. Cochrane and Campbell Equity methods group http://methods.cochrane.org/equity/projects/evidence-equity/progress-plus Accessed 25th June 2018

25. Moore S and Kawachi I.Twenty years of social capital and health research: a glossary.J Epidemiol Community Health. 2017 May;71(5):513-517. doi: 10.1136/jech-2016-208313.

26. Cochrane Multiple Sclerosis and Rare Diseases Review Group (http://msrdcns.cochrane.org/) Accessed $1^{\text {st }}$ December 2016

27. Avasarala JR, O'Donovan CA, Roach SE et al. Analysis of NAMCS data for multiple sclerosis, 1998-2004. BMC Medicine 2007;5:6 
1 28. Bjorkenstam $\mathrm{C}$, Tinghog $\mathrm{P}$, Brenner $\mathrm{P}$ et al. Is disability pension a risk indicator

2 for future need of psychiatric healthcare of suicidal behaviour among MS patients- a

3 nationwide register study in Sweden? BMC Psychiatry. 2015;15:286

4 29. Buchanan RJ, Wang S, Tai-Seale M and Ju H. Analyses of nursing home

5 residents with multiple sclerosis and depression using the Minimum Data Set.

6 Multiple Sclerosis 2003;9:171-88.

7 30. Buchanan RJ, Zuniga MA, Carrillo-Zuniga G et al. Comparisons of Latinos,

8 African Americans and Caucasians with Multiple Sclerosis. Ethnicity and Disease.

$9 \quad 2010 ; 20: 451-57$

10 31. Buchanan RJ, Martin RA, Zuniga $M$ et al. Nursing home residents with multiple sclerosis: comparisons of African American residents to white residents on admission. Multiple Sclerosis 2004;10:660-67

32. Buchanan RJ, Wang S, Stuifbergen et al. Urban/rural differences in the use of physician services by people with multiple sclerosis. NeuroRebilitation. 2006;21:17787.

33. Buchanan RJ, Stuifbergen A, Chakravorty BM et al. Urban/rural differences in access and barriers to health care for people with multiple sclerosis. J Health Hum Serv Adm. 2006;29(3):360-75

34. Buchanan RJ, Martin RA, Wang S, Kim M. Racial analyses of longer-stay nursing home residents with multiple sclerosis. Ethnicity and Disease. 2006;16:15965

35. Buchanan RJ, Wang S, Zhu L and Kim M. Rural-Urban Comparisons of Nursing Home Residents with Multiple Sclerosis. The Journal of Rural Health. 2004;20:8591.

36. Buchanan RJ, Zhu L and James W. Urban/rural differences in health insurance coverage among people with multiple sclerosis. Disability and Rehabilitation. 2007;29:1890-98

37. Buchanan RJ, Schiffer R, Wang S et al. Satisfaction with Mental Health Care Among People with Multiple Sclerosis in Urban and Rural Areas. Psychiatric Services. 2006;57:1206-9

38. Finlayson M, Plow M and Cho C. Use of Physical Therapy Services among Middle-Aged and Older Adults with Multiple Sclerosis. Physical Therapy. 2010;90:1607-18

39. Finlayson ML, Cho CC. A Profile of Support Group Use and Need Among Middle-Aged and Older Adults with Multiple Sclerosis. Journal of Gerontological Social Work. 2011.54:475-93

40. Garcia J and Finlayson M. Mental health and mental health service use among people ages $45+$ with Multiple Sclerosis. Canadian Journal of Mental Health. 2005;24:9-22 
1 41. lezzoni LI, Ngo LH and Kinkel RP. Working -age persons with multiple sclerosis and access to disease-modifying medications. Multiple Sclerosis. 2008;14:112-22.

42. lezzoni LI, Rao SR and Kinkel RP. Patterns of mobility aid use among workingage persons with multiple sclerosis living in the community in the United States. Disability and Health Journal. 2009;2:67-76

43. Johnson KL, Bamer AM, Yorkston KM and Amtmann D. Use of cognitive aids and other assistive technology by individuals with multiple sclerosis. Disabil Rehabil Assist Technol. 2009;4:1-8.

44. Marrie RA, Cutter G, Tyry T et al. Disparities in the management of multiple sclerosis-related bladder symptoms. Neurology 2007;68:1971-78

45. Marrie RA, Horwitz R, Cutter $G$ et al. The burden of mental comorbidity in multiple sclerosis: frequent, underdiagnosed, and undertreated. Multiple Sclerosis. 2009;15:385-92.

46. Marrie RA, Bernstein CN, Peschken CA et al. Health care utilization before and after intensive care unit admission in multiple sclerosis. Multiple Sclerosis and Related Disorders. 2015;4:296-303

47. McKay KA, Tremlett $H$, Zhu $F$ et al. A population-based study comparing multiple sclerosis clinic users and non-users in British Columbia, Canada. European Journal of Neurology2016;23:1093-1100.

48. Minden SL, Frankel D, Hadden L and Hoaglin DC. Access to health care for people with multiple sclerosis. Multiple Sclerosis. 2007;13:547-58

49.Minden SL, Hoaglin DC, Hadden L et al. Access to and utilization of neurologists by people with multiple sclerosis. Neurology. 2008;70:1141-49

50. Mosley LJ, Lee GP, Hughes ML and Chatto C. Analysis of symptoms, functional impairments, and participation in occupational therapy for individuals with multiple sclerosis. Occupational Therapy in Health Care. 2004;17:27-43

51. Owens T, Evangelou N and Whynes DK. Rationing and deprivation: diseasemodifying therapies for multiple sclerosis in the United Kingdom. Eur J Health Econ. 2013;14:315-21.

52. Peters TJ, Somerset M, Campbell R and Sharp DJ. Variables associated with attendance at, and the perceived helpfulness of, meetings for people with multiple sclerosis. Health and Social Care in the Community. 2003;11:19-26

53. Plow $\mathrm{M}, \mathrm{Cho} \mathrm{C}$ and Finlayson $\mathrm{M}$. Utilization of health promotion and wellness services among middle-aged and older adults with multiple sclerosis in the mid-west US. Health Promotion International. 2010;25:318-330.

54. Putnam $M$ and Tang F. Multiple sclerosis, aging and support service utilization. The Journal of Rehabilitation. 2007; 73(4):3-14

55. Ribes Garcia S, Gomez-Pajares F, Puig CA. Description of the Characteristics of Multiple Sclerosis Patients in the Region of Valencia (Spain) Who Requested 
1 Treatment with Disease-Modifying Drugs during the 2005-14 Decade. Eur Neurol.

2 2016;75:274-81

3 56.Roessler RT and Gitchel WD. Severity Employment, and Gender: Factors 4 Influencing Independence for Adults with Multiple Sclerosis. Journal of

5 Rehabilitation. 2013;79:33-45

6 57. Shabas $D$ and Heffner M. Multiple sclerosis management for low-income 7 minorities. Multiple Sclerosis. 2005;11:635-40.
58. Sundstrom P, Nstrom L, Svennignsson A, Forsgren L. Sick leave and professional assistance for multiple sclerosis individuals in Vasterbotten County, northern Sweden. Multiple Sclerosis. 2003;9:515-20.

59. Vickrey BG, Shatin D, Wolf SM et al. Management of multiple sclerosis across managed care and fee-for-service systems. Neurology..2000;55:1341-45

60. Williams RM, Turner AP, Hatzakis M et al. Prevalence and correlates of depression among veterans with multiple sclerosis. Neurology 2005;64:75-80.

61. Windt R, Glaeske $G$ and Hoffmann F. Treatment of multiple sclerosis in Germany: an analysis based on claims data of more than 30,000 patients. Int $\mathrm{J}$ Clin Pharm. 2013;35:1229-35

62. Wools A, Dapper EA, de Leeuw JR. Colorectal cancer screening participation: a systematic review. Eur J Public Health. 2016 Feb;26(1):158-68.

63. Gnavi R, Migliardi A, Demaria M, Petrelli A, Caprioglio A, Costa G. Statins prescribing for the secondary prevention of ischaemic heart disease in Torino, Italy. A case of ageism and social inequalities. Eur J Public Health. 2007 Oct;17(5):492-6.

64. Dourthit N, Kiv S, Dwolatzky T, Biswas S.. Exposing some important barriers to health care access in the rural USA. Douthit N et al. Public Health.2015; 129(6):611-20.

65. Wang G, Marrie RA, Fox RJ, Tyry T, Cofield SS, Cutter GR, Salter A. Treatment satisfaction and bothersome bladder, bowel, sexual symptoms in multiple sclerosis. Mult Scler Relat Disord. 2018 Feb;20:16-21.

66. Henning A, Wehrberger M, Madersbacher S et al. Do differences in clinical symptoms and referral patterns contribute to the gender gap in bladder cancer? BJU Int. 2013 Jul;112(1):68-73.

67. Johnson EK, Daignault S, Zhang Y, Lee CT. Patterns of hematuria referral to urologists: does a gender disparity exist? Urology. 2008 Sep;72(3):498-502

68. Fradgley EA, Paul CL, Bryant J. A systematic review of barriers to optimal outpatient specialist services for individuals with prevalent chronic diseases: what are the unique and common barriers experienced by patients in high income countries? Int J Equity Health. 2015 Jun 9;14:52. 
1 69. Calocer F, Dejardin O, Droulon K et al. Socio-economic status influences access 2 to second-line disease modifying treatment in Relapsing Remitting Multiple Sclerosis 3 patients. PLoS One. 2018 Feb 1;13(2):e0191646.

4 70. National Institute for Health and Care Excellence. Multiple Sclerosis in adults: 5 management. Clinical guideline 186. National Institute for Health and Care 6 Excellence. 2014 https://www.nice.org.uk/guidance/CG186/chapter/1-

7 Recommendations\#ms-symptom-management-and-rehabilitation-2 accessed $26^{\text {th }}$ 8 June 2018

9 71. Gerhard L, Dorstyn DS, Murphy G, Roberts RM. Neurological, physical and analysis. J Health Psychol. 2018 Feb 1:1359105318755262

72. Raggi A, Covelli $\mathrm{C}$, Schiavolin $\mathrm{S}$ et al. Work-related problems in multiple sclerosis: a literature review on its associates and determinants. Disability and Rehabilitaiton;38:936-44.

73. Nguyen A, Mosadeghi S, Almario CV. Persistent digital divide in access to and use of the Internet as a resource for health information: Results from a California population-based study. Int J Med Inform. 2017 Jul;103:49-54.

74. Lonergan R, Kinsella K, Fitzpatrick $P$ et al. Unmet needs of multiple sclerosis patients in the community. Mult Scler Relat Disord. 2015 Mar;4(2):144-50

75. Arksey H, O'Malley L. Scoping studies: Towards a Methodological Framework. Int J Soc Res Methodol. 2005;8(1):19-32

76. Tricco AC, Lillie E, Zarin W et al. A scoping review on the conduct and reporting of scoping reviews. BMC Med Res Methodol. 2016 Feb 9;16:15 
1

2

3 